\title{
Assessment of Accuracy of Continuous Noninvasive versus Invasive Method of Hemoglobin Estimation in Patients Undergoing Pituitary Surgery
}

\author{
Indu Kapoor ${ }^{1}$ Charu Mahajan ${ }^{1}$ Ruhi Mamuliya ${ }^{1}$ Hemanshu Prabhakar ${ }^{1}$ \\ ${ }^{1}$ Department of Neuroanaesthesiology and Critical Care, \\ Neurosciences Centre, All India Institutes of Medical Sciences, \\ New Delhi, India

\begin{abstract}
Address for correspondence Indu Kapoor, MD, Department of Neuroanaesthesiology and Critical Care, Neurosciences Centre, All India Institutes of Medical Sciences, New Delhi 110029, India
\end{abstract} \\ (e-mail:dr.indu.me@gmail.com).
}

J Neuroanaesthesiol Crit Care 2018;5:168-172

Aim Determination of hemoglobin $(\mathrm{Hb})$ concentration by standard methods is time consuming, invasive, and intermittent. Noninvasive ( $\mathrm{NI}$ ) methods of $\mathrm{Hb}$ estimation are less time consuming, and reduce the risk of infection, number of required working personnel, and long-term costs. In this study, we aimed to find the accuracy of Hb values at various time points using noninvasive ( $\mathrm{NI}) \mathrm{Hb}$ monitoring and standard invasive techniques such as laboratory (LabHb) and arterial blood gas (ABG).

Methods All American Society of Anesthesiologists (ASA) physical grade I and II adult patients between 18 and 65 years of either gender undergoing pituitary surgery under general anesthesia were included over a period of 1 year. Samples were collected for $\mathrm{Hb}$ estimation from the arterial line $(\mathrm{aHb})$ using $\mathrm{ABG}$ analyzer machine and LabHb using automated $\mathrm{Hb}$ analyzer. Simultaneously, $\mathrm{Hb}$ reading from the $\mathrm{NI} \mathrm{Hb}$ monitor was recorded using Masimo Spot Hemoglobin Check Device. Bland-Altman plot was used to find out agreement between $\mathrm{Hb}$ values drawn from three different techniques. $\mathrm{A}$ $p$-value $<0.05$ was considered significant.

Results A total of 30 patients participated in the study. The male to female ratio was 13:17. Statistical analysis showed poor correlation between the invasive and NI methods of $\mathrm{Hb}$ estimation.

Conclusion $\mathrm{NI}$ method of $\mathrm{Hb}$ estimation may be successfully used in clinical practice, replacing estimation from ABG analysis or laboratory tests. However, NI method cannot replace the invasive methods of $\mathrm{Hb}$ estimation.

\section{Introduction}

Neurosurgical procedures may involve massive and rapid blood loss. Decision to measure the hemoglobin $(\mathrm{Hb})$ level and when to transfuse blood is important and crucial. In operating room, $\mathrm{Hb}$ estimation is largely relied on values obtained from arterial blood gas (ABG) analysis. Until recently, only invasive monitoring techniques were available for the estimation of $\mathrm{Hb}$. Noninvasive (NI) $\mathrm{Hb}$ monitoring is found to be more efficient, less expensive, and preferred by patients compared with invasive Hb monitoring. ${ }^{1}$ A new NI device, Masimo Spot Hemoglobin Check Device, received the

received

May 16, 2018

accepted after revision

August 2, 2018

published online

September 20, 2018
Food and Drug Administration (FDA) clearance that allows for quick and noninvasive (NI) checking of total $\mathrm{Hb}$, oxygen saturation $\left(\mathrm{SpO}_{2}\right)$, pulse rate, and perfusion index (PI). Continuous, NI Hb monitoring provides clinicians with the trending changes in $\mathrm{Hb}$, and has the potential to alter red blood cell transfusion decision making. Awada et al's suggestion to add NI monitor to standard monitoring resulted in decreased utilization of blood products during intraoperative period specifically in neurosurgical procedures where excessive blood loss is anticipated while facilitating earlier transfusions. ${ }^{2}$ However, it has been observed that the $\mathrm{NI} \mathrm{Hb}$ monitoring may not have sufficient accuracy to minimize the
Copyright $\odot 2018$ Indian Society of Neuroanaesthesiology and Critical Care

\section{License terms}

10.1055/s-0038-1671690.

ISSN 2348-0548.

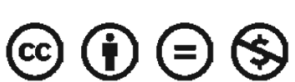


need for invasive $\mathrm{Hb}$ monitoring, but it may allow continuous monitoring of $\mathrm{Hb}$ and could guide clinicians as to the need for invasive monitoring. ${ }^{3}$ In our study, we aimed to find out the accuracy of $\mathrm{NI} \mathrm{Hb}$ monitor for estimating $\mathrm{Hb}$ values by comparing it with invasive methods such as arterial and laboratory samples.

\section{Methods}

This study was conducted after taking approval from institute ethics committee (Ref: IEC/NP-315/07.08.2015, RP-13/2015). After taking consent, all American Society of Anesthesiologists (ASA) physical grade I and II adult patients between 18 and 65 years of either gender undergoing pituitary surgery (transnasal and trans-sphenoidal) were included. Patients who refused consent, those with a history of peripheral vascular disease, hemoglobinopathy, and sickle cell disease and patients whose PI on Masimo mo nitor was $<1.4$ were excluded. A day before surgery, pre-anesthetic checkup was done. Patients were fasted for 8 hours before the scheduled surgery and received pre-medication with glycopyrrolate $0.2 \mathrm{mg}$ via intramuscular route, 1 hour prior to surgery. Anesthesia was induced with fentanyl $2 \mu \mathrm{g} / \mathrm{kg}$ and propofol 1.5 to $2 \mathrm{mg} / \mathrm{kg}$. Tracheal intubation was facilitated with rocuronium $1 \mathrm{mg} / \mathrm{kg}$. Sevoflurane (0.8-1.2 minimum alveolar concentrations) in a mixture of $\mathrm{O}_{2}$ and $\mathrm{N}_{2} \mathrm{O}(1: 2)$ was used for the maintenance of anesthesia, together with fentanyl $1 \mu \mathrm{g} / \mathrm{kg}$, as an intermittent bolus to maintain analgesia. Rocuronium $0.2 \mathrm{mg} / \mathrm{kg}$ every 30 minutes was used intermittently to provide neuromuscular blockade. A blood sample of $1 \mathrm{~mL}$ was obtained using a radial artery catheter immediately after induction of anesthesia, but before the start of surgery and approximately every hour thereafter till we removed the arterial line at the end of surgery. Samples were collected for $\mathrm{Hb}$ estimation from the arterial sample $(\mathrm{aHb})$ using ABG analyzer machine (Eschweiler GmbH \& Co. KG) and laboratory (LabHb) using automated hemoglobin analyzer. Simultaneously, the $\mathrm{Hb}$ reading from the $\mathrm{NI} \mathrm{Hb}$ monitoring was recorded using Masimo Spot Hemoglobin Check Device, Masimo Spot Hemoglobin Check Device (Pronto; Irvine, California, United States). Other values displayed on the monitor, such as the PI was also recorded. Hb values at a PI $<1.4$ are not considered reliable as these are not recommended by the manufacturer, hence not included for analysis. The blood oxygen saturation values from the standard pulse oximeter $\left(\mathrm{SpO}_{2}\right)$, NI $\left(\mathrm{SpO}_{2}\right)$, and $\mathrm{ABG}$ were noted. Also, the core body temperature was noted each time the values were recorded.

Statistical analysis was performed using Stata 12.0 (StataCorp LP, College Station, Texas, United States). Data were presented as number (percentage) or mean \pm standard deviation (SD) as appropriate. Bland-Altman plot was added to find out the agreement between $\mathrm{Hb}$ values drawn from three different techniques. The $p$-value $<0.05$ was considered statistically significant.

\section{Results}

A total of 30 patients participated in the study, which was conducted over a period of 1 year. None of the patient was excluded from the study. The male to female ratio was 13:17.
The other demographic characteristics including mean age of 40.83 (17.03) and mean weight of 66.5 (12.31). Hb could be measured up to two time points (Hb1 and $\mathrm{Hb} 2$ ) in 30 patients, up to three time points ( $\mathrm{Hb} 1, \mathrm{Hb} 2$, and $\mathrm{Hb} 3$ ) in 27 patients, and up to four time points ( $\mathrm{Hb} 1, \mathrm{Hb} 2, \mathrm{Hb} 3$, and $\mathrm{Hb} 4$ ) in only 18 patients. This was due to the difference in duration of surgery ( - Fig. 1). At different time points, there was a trend, which showed $\mathrm{NI} \mathrm{Hb}$ monitor with the highest $\mathrm{Hb}$ values followed by $\mathrm{Hb}$ values obtained from arterial sample and the laboratory test ( - Fig. 2).

- Table 1 shows the correlation between different techniques of Hb estimation. ( - Fig. 3) displays the Bland-Altman plot of the relationship between the observed differences between $\mathrm{Hb}$ values of Laboratory and $\mathrm{NI} \mathrm{Hb}$ monitor and the mean of the two measures. Limits of agreement (horizontal lines) indicate that 28 of the 30 estimates of NI Hb values were within the limits. The limits of agreement are defined as the mean difference $\pm 2 \mathrm{SD}$, and the calculated lower and upper limits for Laboratory and NI were between -4.5 and +2.7 . ( - Fig. 4 ) displays the Bland-Altman plot of the relationship between the observed differences between $\mathrm{Hb}$ values of arterial and $\mathrm{NI} \mathrm{Hb}$ monitor and the mean of the two measures. Limits of agreement (horizontal lines) indicate that 28 of the 30 estimates of $\mathrm{NI} \mathrm{Hb}$ values were within the limits. The limits of agreement are defined as the mean difference $\pm 2 \mathrm{SD}$, and the calculated lower and upper limits for Laboratory and NI are between-4.6 and +3.6. ( - Fig. 5) displays the Bland-Altman plot of the relationship between the observed differences between $\mathrm{Hb}$ values of laboratory and arterial and the mean of the two measures. Limits of agreement (horizontal lines) indicate that 29 of the

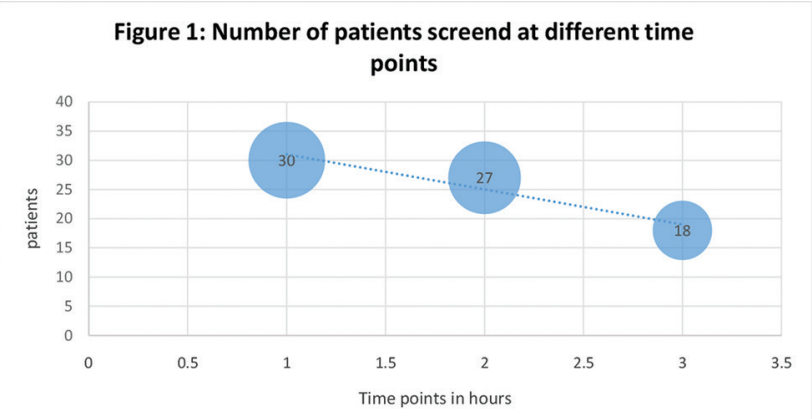

Fig. 1 Number of patients screened at different time points.

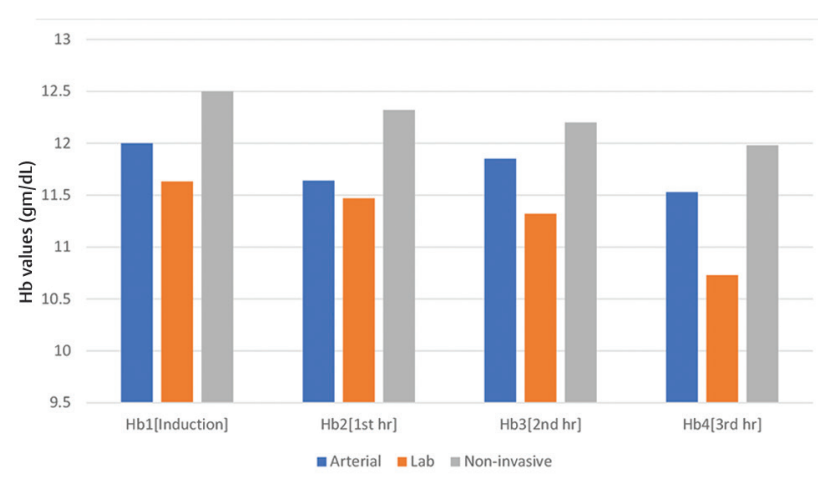

Fig. 2 Hemoglobin estimation at different time points. Hb, hemoglobin; hr, hour. 
Table 1 Correlation between different methods of hemoglobin estimation

\begin{tabular}{|l|l|l|l|}
\hline & Total patients & Correlation & Significance \\
\hline Arterial and laboratory & 30 & 0.7040 & 0.0000 \\
\hline Laboratory and noninvasive & 30 & 0.2355 & 0.2103 \\
\hline Arterial and noninvasive & 30 & 0.1059 & 0.5775 \\
\hline
\end{tabular}

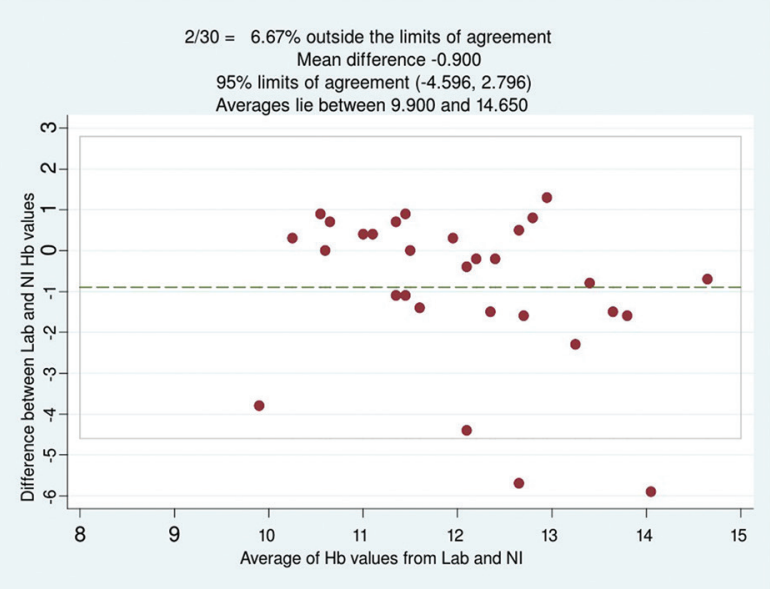

Fig. 3 Bland-Altman plot of correlation between observed differences between laboratory and NI. Hb, hemoglobin; NI, noninvasive.

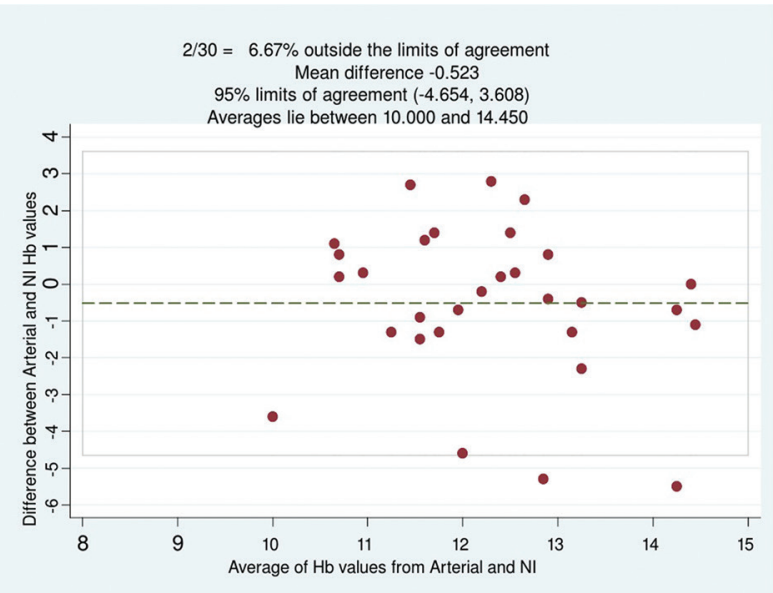

Fig. 4 Bland-Altman plot of correlation between observed differences between arterial and NI. Hb, hemoglobin; NI, noninvasive.

30 estimates of arterial $\mathrm{Hb}$ values were within the limits. The limits of agreement are defined as the mean difference $\pm 2 \mathrm{SD}$, and the calculated lower and upper limits for laboratory and $\mathrm{NI}$ were between-1.6 and +2.4. In ( - Fig. $\mathbf{6})$, the regression lines show the relation between the laboratory and $\mathrm{NI} \mathrm{Hb}$ trends. ( - Fig. 7) shows the relationship between the arterial and NI trends, and ( - Fig. 8) shows the relationship between the arterial and laboratory trends, respectively.

\section{Discussion}

Determination of $\mathrm{Hb}$ concentration by standard methods is time consuming, invasive, and intermittent. NI Hb monitoring devices have the potential for detecting sudden changes

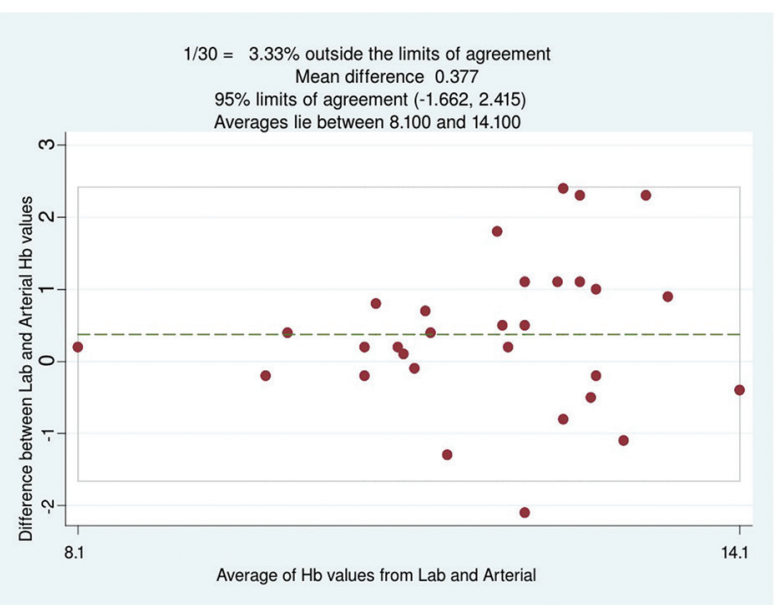

Fig. 5 Bland-Altman plot of correlation between observed differences between arterial and laboratory. $\mathrm{Hb}$, hemoglobin.

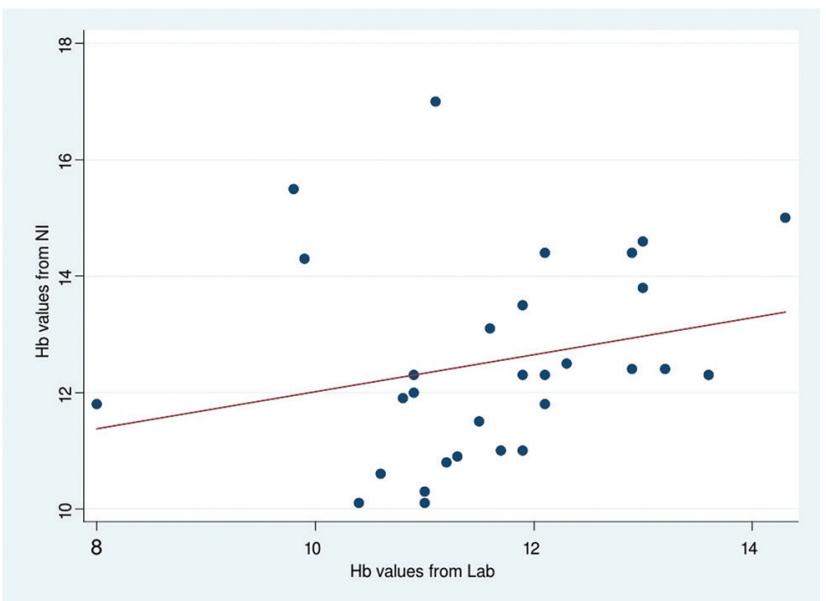

Fig. 6 Scatter diagram showing relationship between laboratory and $\mathrm{NI} \mathrm{Hb}$ values trends. $\mathrm{Hb}$, hemoglobin; $\mathrm{NI}$, noninvasive.

in a patient's $\mathrm{Hb}$ concentration in blood. This $\mathrm{NI}$ method of $\mathrm{Hb}$ determination provides a comfortable environment to the patient as well as reduces the risk of infection, number of required working personnel, and long-term costs. However, the accuracy of NI method can be influenced by many clinical factors such as perfusion state, temperature, a large volume shift, type of infused fluid, and age of the patient. In our study, we aimed to assess the accuracy of NI method of Hb estimation over invasive methods. Based on the results of the Bland-Altman plots, in our study, the calculated $95 \%$ confidence interval (CI) for the difference calculated on the laboratory and NI Hb value was4.5 and +2.7. Therefore, for an actual $\mathrm{Hb}$ value of $12 \mathrm{mg} / \mathrm{dL}$, it could be reported to be either as low as $7.5 \mathrm{mg} / \mathrm{dL}$ or as high as $14.7 \mathrm{mg} / \mathrm{dL}$. It is definitely considered to be clinically 


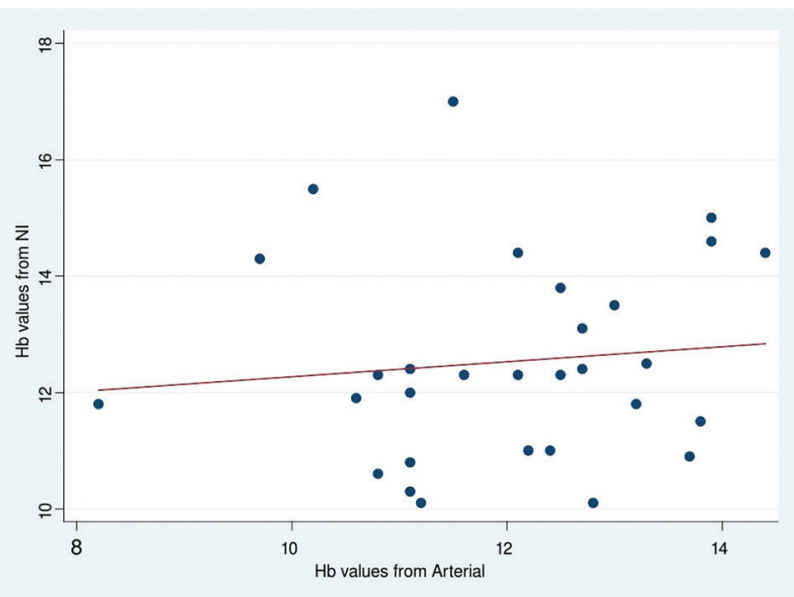

Fig. 7 Scatter diagram showing relationship between arterial and $\mathrm{NI}$ $\mathrm{Hb}$ values trends. $\mathrm{Hb}$, hemoglobin; NI, noninvasive.

significant, and management of patients on the basis of this report could be hazardous. Again, for arterial and NI Hb values on the basis of same plot, there would be wide upper and lower $\mathrm{Hb}$ range difference which is not acceptable. The reason for this wide range could be smaller sample size or inaccuracy of NI Hb estimation method. The correlation coefficient between the NI and laboratory values was 0.235 , and between the NI and ABG analysis values was 0.105 , which showed no correlation. However, Hb values between arterial and laboratory analysis showed a good correlation (correlation coefficient of 0.707), which might serve as an explanation for inaccuracy of $\mathrm{NI} \mathrm{Hb}$ estimation method thereby leading to wide variation in other two paired groups. As per the result of Scatter diagrams, invasive and NI methods of $\mathrm{Hb}$ estimation showed poor correlation between themselves ( - Figs. 6 and 7). However, the scatter diagram between arterial and laboratory $\mathrm{Hb}$ estimation methods showed good correlation (-Fig. 8).

Findings from our study suggest that $\mathrm{NI} \mathrm{Hb}$ monitor can neither replace $A B G$ sampling $(\mathrm{aHb})$ for $\mathrm{Hb}$ estimation nor $\mathrm{Hb}$ estimation from laboratory tests. Though both $\mathrm{NI}$ and $\mathrm{aHb}$ methods provide immediate $\mathrm{Hb}$ values during intraoperative period for $\mathrm{Hb}$ estimation, continuous real time $\mathrm{Hb}$ monitoring is the advantage with $\mathrm{NI}$, which is not possible with aHb since it requires intermittent blood sampling. We also compared both invasive methods of $\mathrm{Hb}$ estimation techniques, LabHb and ABG analysis, and found a good correlation between the two (correlation coefficient of 0.7040 ). Hb estimation by NI monitor depends on the adequacy of blood flow to the finger, which is indirectly reflected by PI. PI is a calculated value, which is displayed on $\mathrm{NI}$ monitor, and $\mathrm{Hb}$ values displayed on monitor with PI values of $<1.4$ are not considered reliable. The alteration in finger perfusion either underestimates or overestimates the true $\mathrm{Hb}$ values depending on the decreased or increased tissue perfusion. So, PI is an important clinical indicator of actual $\mathrm{Hb}$ values on NI monitor. According to Khanna et al, NI Hb monitor does not have sufficient accuracy to minimize the need for invasive $\mathrm{Hb}$ monitoring, which includes both $\mathrm{ABG}$ and laboratory sample. ${ }^{4}$ One limitation of their study was that they could not

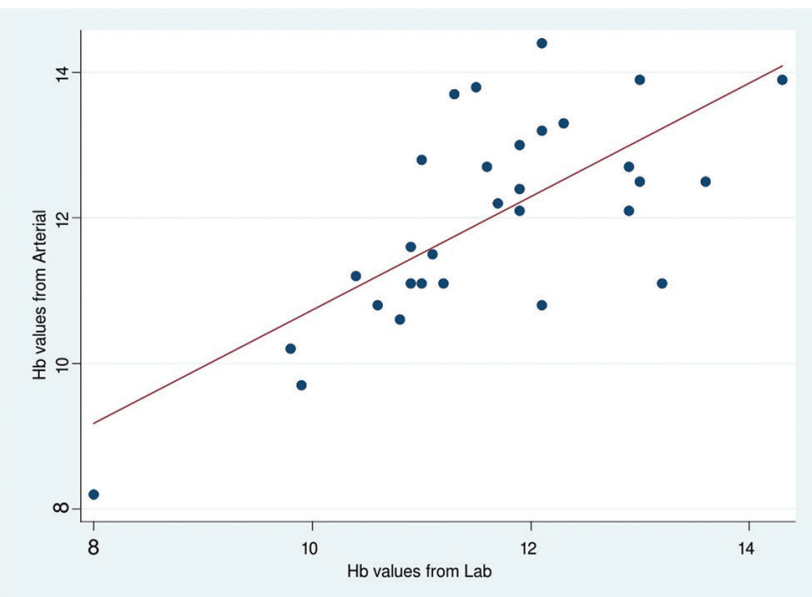

Fig. 8 Scatter diagram showing relationship between arterial and laboratory $\mathrm{Hb}$ values trends. $\mathrm{Hb}$, hemoglobin.

use NI monitor properly in 8 patients out of 30 due to PI value $<1.4$. Throughout surgery in our study, all patients had PI values $>1.4$. In contrast, Vora and Desai conducted a study that was performed in the intensive care unit and compared transcutaneously spectroscopically $\mathrm{NI}$ measured $\mathrm{Hb}$ values with venous $\mathrm{Hb}$ values. They concluded that there is a good relation between the two methods for measuring $\mathrm{Hb}$. However, authors further concluded that larger studies are required to validate this NI method in those with conditions that affect the perfusion. ${ }^{5}$ Joseph et al observed that the $\mathrm{NI} \mathrm{Hb}$ monitoring was found to have excellent correlation with invasive $\mathrm{Hb}$ measurement in trauma patients, and its application allows immediate and accurate $\mathrm{Hb}$ measurement. ${ }^{6}$ In our study, we found a poor correlation between $\mathrm{Hb}$ values by invasive and $\mathrm{NI} \mathrm{Hb}$ monitoring methods; however, the main difference between ours and their study was that they compared LabHb and NI, whereas in our study, we compared two invasive methods ( $\mathrm{aHb}$ and $\mathrm{LabHb}$ ) of $\mathrm{Hb}$ estimation with $\mathrm{NI} \mathrm{Hb}$ estimation method. Another difference was the patient population that in our study included non-traumatic patients. In another study by Applegate et al, they compared $\mathrm{NI}, \mathrm{aHb}$, and arterial finger stick blood with LabHb and observed that all three methods provided similar intraoperative guidance regarding increase or decrease in $\mathrm{Hb}$ value, whereas these cannot be used for guide transfusion decision making. ${ }^{\text {B Butwick et }}$ al reported that despite a significant correlation between $\mathrm{NI}$ and laboratory $\mathrm{Hb}$ values, $\mathrm{NI}$ monitor overestimated $\mathrm{Hb}$ values compared with laboratory Hb values. ${ }^{8}$ We also observed the same trend of higher $\mathrm{Hb}$ values with $\mathrm{NI}$ compared with laboratory $\mathrm{Hb}$. However, NI always overestimated $\mathrm{Hb}$ values at different time points compared with arterial $\mathrm{Hb}$ values. In our study, LabHb values were the lowest when compared with $\mathrm{NI}$ and aHb values.

\section{Conclusion}

From our study, we conclude that NI method of Hb estimation may be successfully used in clinical practice; however, this method cannot replace the invasive $\mathrm{Hb}$ estimation methods such as ABG analysis and laboratory method of $\mathrm{Hb}$ estimation. More trials are required to find out the accuracy 
between noninvasive method of $\mathrm{Hb}$ estimation and invasive methods of $\mathrm{Hb}$ estimation. Inclusion of NI method of Hb estimation in standard monitor list could be helpful in instantaneous assessment of blood loss and guiding blood transfusion therapy in patients at risk of bleeding.

\section{Conflict of Interest}

None.

\section{References}

1 Martin JR, Camp CL, Stitz A, et al. Noninvasive hemoglobin monitoring: a rapid, reliable, and cost-effective method following total joint replacement. J Bone Joint Surg Am 2016;98(5):349-355

2 Awada WN, Mohmoued MF, Radwan TM, Hussien GZ, Elkady HW. Continuous and noninvasive hemoglobin monitoring reduces red blood cell transfusion during neurosurgery: a prospective cohort study. J Clin Monit Comput 2015;29(6):733-740
3 Miller RD, Ward TA, Shiboski SC, Cohen NH. A comparison of three methods of hemoglobin monitoring in patients undergoing spine surgery. Anesth Analg 2011;112(4):858-863

4 Khanna P, Rajagopalan V, Singh G, Prabhakar H. A comparison of non-invasive versus invasive methods of haemoglobin estimation in patients undergoing intracranial surgery. South African Journal of Anesthesia and Analgesia. 2014;20:160-163

5 Vora H, Desai P. Invasive versus noninvasive hemoglobin measurement by pulse $\mathrm{CO}-0 x i m e t e r$ in neonates admitted to NICU. J Med Sci 2014;3(1):68-71

6 Joseph B, Pandit V, Aziz H, et al. Transforming hemoglobin measurement in trauma patients: noninvasive spot check hemoglobin. J Am Coll Surg 2015;220(1):93-98

7 Applegate R, Cannesson M, Applegate P, Peiris P, Ladlie B, Torp K. Hemoglobin Change Measurement Accuracy Obtained from 3 Devices during Surgery. Abstract presented at: IARS Annual Meeting; May 6-9, 2017; Washington, DC. Abstract A1786

8 Butwick AJ, Hilton G, Riley ET, Carvalho B. Non-invasive measurement of hemoglobin during cesarean hysterectomy: a case series. Int J Obstet Anesth 2011;20(3):240-245 